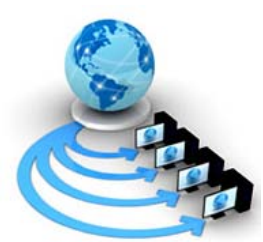

Volume 11, No. 5, September-October 2020

\title{
A NEW MODEL OF COMPARATIVE DIRECTIONS AND PROFILE MATCHING IN THE CARPOOLING COMPUTATIONAL SYSTEMS
}

\author{
Jyoti Ranjan Mohanty \\ Research Scholar \\ Dept. of Computer Application \\ SSSUTMS, Sehore \\ M.P., India
}

\author{
Dr. Jitendra Sheetlani \\ Associate Professor \\ Dept. of Computer Application \\ SSSUTMS, Sehore \\ M.P., India
}

\author{
Dr. Rasmi Ranjan Patra \\ Asst. Professor \\ Dept. of CSA \\ OUAT, Bhubaneswar \\ Odisha, India
}

\begin{abstract}
Carpooling is a system in which the passenger can share the vehicles and by this means the traffic also reduces due to reducing the no. of vehicle on the road. Most of the government and non-government organization has started the implementation of carpooling system. To implement this system various approaches has been developed but it becomes essentials that the selection of optimal distance for picking the passenger for improving the recital of the system. So in this research work, we use graph traversal technique to find the effective path and it is tested to find the optimal solution. The experimental results of the proposed methodology show that our approach is more efficient than the existing approach.
\end{abstract}

Keyword: Carpooling, loT, Graph traversal, BFS, DFS.

\section{INTRODUCTION}

Carpooling means when more than one people want to use their car together for journey from different household to save not only money but also to save environment from pollution through utilizing a smaller amount of fuel and it also gives pleasure to their company during journey [1]. The carpooling services provided through the webpage will act as a boundary between different unknown people, who wants to travel through sharing mode and it needs computation tips only when collectively displacements from their source to each one's destination. Carpooling found to be socially acceptable for the environments and also sustainable technique for sharing journeys during travel. It helps in reducing the release of carbon dioxide $\left(\mathrm{CO}_{2}\right)$, minimizing the congestions in road traffic and also solve the various issues in parking spaces which gives us the power to encourage the carpooling during rise in fuel prices and also in high pollution situation. Due to the rapid growth in transportation which makes it more complicated in order to provide common services for transportation. In addition to this the common people using one vehicle for communication, carpooling helps to lose transportation fees like cost of the fuel, maintenance, toll fees and the burden of driving. IOT use different device that are sufficient enough for communicating and sharing of information among themselves, as this idea makes them potential for applying in active as well as applicable configuration. The main intention of IOT is the commencement of smart intelligent environments or spaces where the possessions like smart city, smart home, smart transport etc. are self-aware for novel and innovative based applications. In IOT, persistence of object and entity (thing) is granted with unique identifier which has capability for receiving or transferring data mechanically from or to a network. The various objects used insight of IOT is RadioFrequency Identification (RFID) sensors, actuators, detectors etc. In a large sense, much of the IOT includes various intelligent computing devices and surrounded sensor systems which are basically used in Vehicle to Vehicle (V2V), Machine to Machine (M2M) communication along with wearable computing devices which are used for different purposes. The concept of IOT is gradually growing its application fields day by day in different fields of technology; therefore its place is secured in the field of transport and traffic management as well. The major problem in current scenario is the increase in number of passenger vehicles (i.e. cars) which is directly proportional related with the growth of population. As a result of this the major problems arise here are severe traffic congestions, accidents, noise and latency in travelling time. Carsharing is the improvised transport model which initiates ride-share/share the ride of a single vehicle by multiple passengers in spite of their source of journey. Here the main purpose is to decrease the availability of total number of vehicle on road at any time and reduce travelling expense of each rider. In true fact, carsharing is the most common general paratransit mode where the passengers create different user groups in order to share a vehicle which moves on their pre-defined routes. Carsharing facilitate ride sharing with passenger vehicles, it is depend on the idea of sharing single passenger vehicle among the others where the owner of the vehicle is third party (subject to business). As a result of this, mostly the users or passengers of the urban areas get a chance to ride by a shared vehicle without having their own 
vehicle and the vehicle can be avail by them after obtaining a standardized key card on the specifically identified designated stations on giving defined wage or reimbursement fees. IOT concept gives the horizon for carsharing with respect to the current situation. The basic purpose of IOT is to offer connectivity for everyone to everything in $24 \mathrm{X} 7$ and at any place, which is vital for carsharing system [2].

The organization of rest of the paper is as done as follows: Section 2 briefly discusses the work done by the various researchers in carpooling system. Section 3 presents the proposed work and algorithm developed for the implementation of carpooling system. In section 4 experimental results and its analysis is illustrated. And last section presents the overall conclusion of the work and their future aspects.

\section{RELATED WORK}

This section of the research paper discusses the earlier work by the various researchers and authors to implement carpooling system which is explained below:

Grgurevic et al., [2] analyzed the probable request of the thought of Internet of Things (IoT) in the traffic surroundings based on the exemplar of the carpooling/ridesharing structure with the use of a personal vehicle - the car sharing model. The research has been demeanors via surveying and interviewing traffic method participants (i.e. users) who commonly use modern communiqué devices, technologies, and services. Beleaguered users are memorable with the issues of the carpooling/ridesharing system. Based on the research psychotherapy results, it is probable to recognize the factors of the possible application of the IoT solutions in the progress of car-sharing model. Sofia Liakopoulou et al.,[3] investigation was made over one step forward towards coordination in carpooling which helps the philosopher about the municipal trips for the students of Thessaloniki, so that the students can go to their close by home town cities and viceversa. In present time, the mobility is restricted due to absence of substitute mobility options, greater price of car driving and also its maintenance along with the less number of services offered through inter-urban motor vehicle system of Thessaloniki. Depend on the outcomes obtained by the University carpooling system, an on-line survey by means questionnaires were prepared and answered then review over the out comings of the same was conducted over the university students which are situated in the Thessaloniki (Aristotle University, University of Macedonia and Technical Institution of Thessaloniki) for discover of choice preference concerned to construct good carpooling system which should be exclusively managed and used by the members of the academic group of people. The investigation of the study focused on the constructive carriage out of the response given by the students. As per the survey result industry model of carpooling and its base configuration was projected in order to provide the university students and the educational, managerial employees of the above said universities. Abubakr Alabbasi et al., [4] a free dispersed model was proposed and also enlarged i.e. Deep Pool. It uses deep Q-network (DQN) procedure to acquire knowledge on the most advantageous transmit policies by interacting through the present situation. Except that, Deep Pool will also proficiently add the various statistics related to the journey the role of deep learning model is to manage the vehicles departure in order to increase the services for travel sharing. Deep Pool performs well than its expectations in cab trips of New York City by providing some extra policies i.e. do not send out the vehicles to those areas as ride-sharing in which scenario it is clearly predictable. At last,
Deep Pool is used rapidly in dynamic environments which support distributed approach. In this approach every participated motor vehicle solve its own DQN separately having proper coordination. Xiao Qiang et al., [5] suggested the carpooling using taxi in urban a clustering algorithm which rely on data pasture energy along with position spacing is prepared to explicate the difficultness of clustering in taxi carpooling which runs on urban roads. The basic purpose of using data pasture energy is to calculate the energy at the ground level for every data point of traveler taxi off point dataset. For better understanding of the taxi clustering, each data point is divided into the midpoint, external and each cluster subset data points which are distinguished as per the field value and the entry value by multiplication of each data point field value with that of point spacing. By utilizing compression, partition and Dunn validity index, analysis and comparison is made between conventional and planned algorithm. The suggested algorithms clustering effect is no doubt better than the persons of the orthodox clustering algorithm. The algorithm has better quality clustering results from the container of cluster numbers i.e. 25,249 and 599 for the dataset of taxi course and assured promptness in both allocation of space and also in unbalanced allotment of space as per the time allocation. To get innovative thoughts and appropriate method for the cluster learning of the vehicles operated in urban traffic road this algorithm is considered as the most appropriate for the same. Chaitrali Dangareand Ms. Gouni Akila, [6] projected to build up an android based function which helps user to share expenditure, not to be concerned as regards hiring a cab and production new connections. D.Selvaraj et al., [7] proposed an IOT based system is residential in nature to supply authorization to any emergency vehicle with aid of employing Radio Frequecy Identification (RFID) expertise by rotating all the red lights to green on the pathway of the emergency vehicle. In adding to the green wave path, the organization will track a stolen vehicle when it passes during a traffic light with help of RFID. This method suggest a diminish in tradition coming up time for traffic permission is achieved. Drivers have a less pressure to handle vehicles and can diminish accident rates to a greater extent which make its longevity. The projected method can be a large reprieve to the traffic control sector to handle traffic in a large way. This RFID \& IOT employed detecting system is reasonably effectual and perform as a powerful system.

\section{PROPOSED METHODOLOGY}

For implementing the carpooling system graph traversal method is used to find the shortest or minimum route which can be depth first search or breadth first search techniques of graph traversal. Graph traversal is a technique which is used for searching each vertex or nodes in a graph. In search process, this method is used to decide the traversing order of vertices is visited and determines the edges to be used in search process without generating loops which means that visit all the vertices of graph without getting into looping path.

\section{A. Proposed Steps}

As in given system our motto is to build a system which can find

1) All possible Routes.

2) Passengers on each Route.

3) Distance need to travel on each Route. 
For providing such information about any route, we need to do following things over all the nodes and their connecting roads

1) Generate graph for all roads and stoppage.

2) Find all possible Ways for Travelling for Start to End.

3) Track all passengers on all routes.

4) Find distances need to be travelled in each route.

For this entire, we will start this by generating a graph with the help of nodes and edges between it. As these details will be entered by the user like Total Nodes, Total Roads, Start-End-Distance for each road, with help of this information a graph can successfully designed. After his user needs to enter his/her starting and ending point. These are the start and ending location for the vehicle which is going to be pooled. Now as the graph is generated so we can find all the possible ways. There are many ways to traverse the graph. Mostly DFS (Depth First Search) \& BFS (Breadth First Search) are used for this task. So these methods will tell us all the possible ways by which the driver can reach to the final destination. Now we have all possible ways, now first task is to find the find the total distance which driver need to travel on which ways. We just need to add all the weight of the edges to calculate the total length of each road. Now the last task is to find the passengers pickups and total passengers which can be picked in the whole drive.

So after all this we have

1) List of all routes.

2) List of distance need to be travelled on each route.

3) Passengers picks of each route.

4) No of passengers can be picked on that route.

With all this any driver can simply calculate which route is more beneficial for him so that he'll have a better choice which is depicted through graph presented in Figure I.

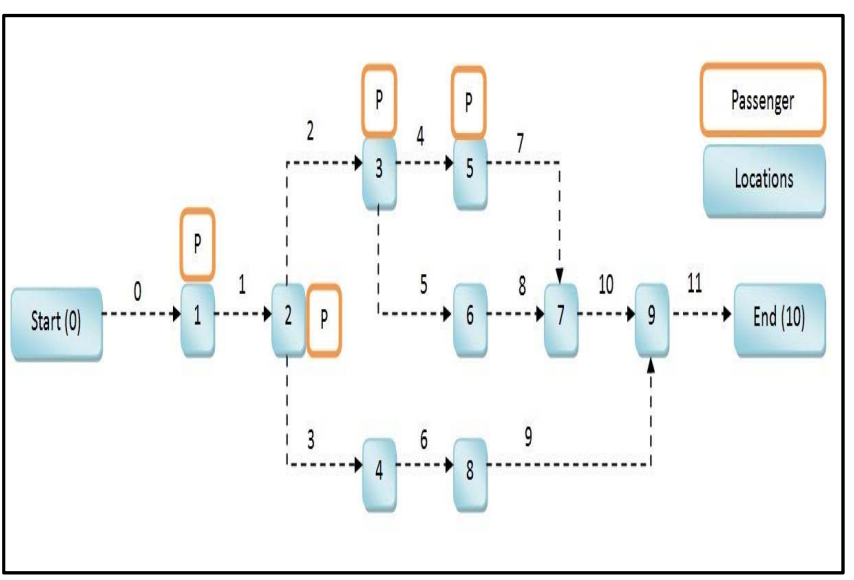

Figure I. Graph for Carpooling example

The existing information derived from the Figure 1 . is

1) Total number of Stoppages $>11$

2) Total number of Roads $>12$

3) Start, End Distance of each Road

4) Starting Point of Driver $>0$

5) Ending point of driver $>10$

6) Capacity of Car $>4$

7) How Many passengers are there $>4$

8) Location of Passengers $>1,2,3 \& 5$

\begin{tabular}{|c|c|c|c|}
\hline Road No. & Start Node & End Node & Distance \\
\hline 1 & 0 & 1 & 0 \\
\hline 2 & 1 & 2 & 1 \\
\hline 3 & 2 & 3 & 2 \\
\hline 4 & 2 & 4 & 3 \\
\hline 5 & 3 & 5 & 4 \\
\hline 6 & 3 & 6 & 5 \\
\hline 7 & 4 & 8 & 6 \\
\hline 8 & 5 & 7 & 7 \\
\hline 9 & 6 & 7 & 8 \\
\hline 10 & 7 & 9 & 9 \\
\hline 11 & 8 & 9 & 11 \\
\hline 12 & 9 & 10 & \\
\hline
\end{tabular}

\section{B. Algorithm}

Following is the algorithm used in the carpooling problem with flowchart represented in Figure II.

Step 1: Take the entire car as input source.

Step 2: Generate the graph for all the road connectivity to travel from start and end point.

Step 3: After finding all the road connectivity select start point and end point.

Step 4: Trace all possible route from start end to destination.

Step 5: Track the location of passenger in each route.

Step 6: Calculate the cost and passenger list in each route to select the optimal path from start to end point.

Step 7: Perform profile matching for each passenger.

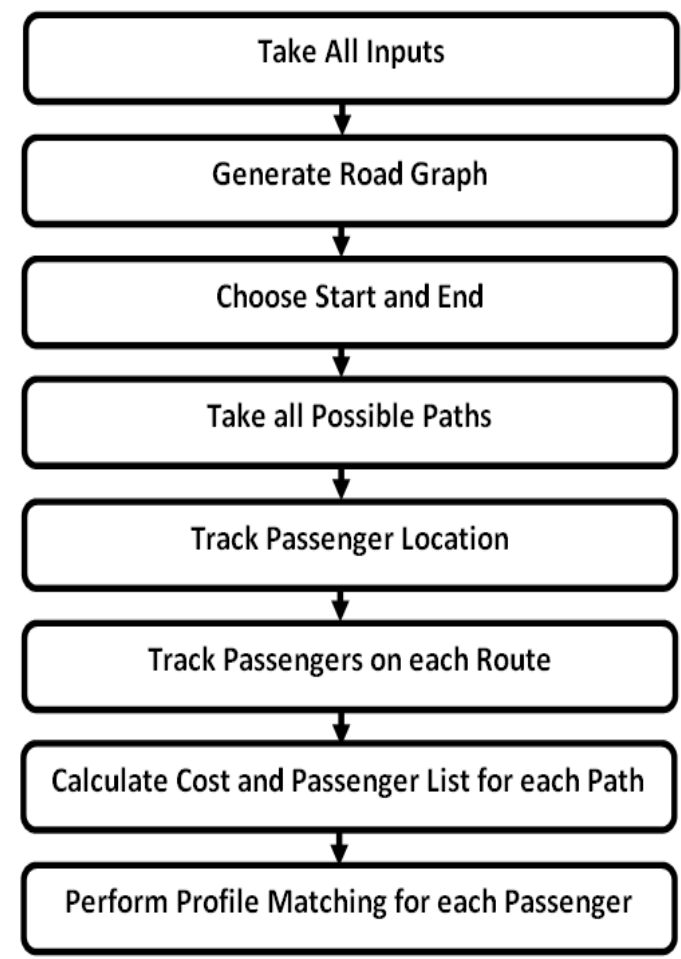

Figure II. Flowchart for Carpooling system 


\section{Pseudo Code for Carpooling System}

\section{\# Writing all input and outputs}

Input :List_Roads[Start_points, End_points, Distance],

List_passengers, Start_point, End_point,

Capacity_of_vehicle

Output : List_final_Routes , List_final_Routes_distance, List_final_pass

\section{\# Takes all inputs and generates Graph}

T1: Graph_generaion(List_Roads)

T3: Graph = Null

T2: ------Connect_nodes(List_Roads[Start_points, End_points])

T 3: ------Assign_distance(List_Roads[Start_points, End_points, Distance])

T4: return Graph

\section{\# Finding all possible ways to travel}

T5: List_final_Routes $=$ Null

T6: While(path(Start_point, End_point))is_available

T7: ------ List_final_Routes . add(path)

T4: return List_final_Routes

\section{\# Finding distance which will be travelled}

T8: Find_distance(List_final_Routes)

T9: List_final_Routes_distance= Nul

T10: for(path_in_List_final_Routes)

T11: -----_List_final_Routes_distance.add(distance(path))

T4: return List_final_Routes_distance

\section{\# Tracking passengers}

T8: Find_passengers(List_final_Routes)

T9: List_final_pass= Nul

T10: for(path_in_List_final_Routes)

T11: ------ List_temp= Null

T35: ------While(capacity_of_vehicle $>1$ )

T11: ------ List_final_Routes_distance.add(distance(path))

T11: ------ List_final_pass.add(List_temp)

T4: return List_final_pass

\section{** All the below follows same pattern}

Graph > Roadmap of all given situations

List_final_Routes $>$ Contains list of all routes

List_final_Routes_distance $>$ Contains length of each path

List_final_pass $>$ Contains list of passengers on each path

\section{EXPERIMENTAL RESULTS}

\section{A. Setup}

The experiment for carpooling system is carry out by means of mutually actual and pretend data. To conclude location of carpool drives and travellers potentials, various set of point location were arbitrarily produced inside the surrounded box of metro cities of India. This research is accomplished on a desktop stand alone machine, using Intel Core i7-10700 @ 4.8GHz, with 16 MB RAM, a secondary storage disk with $7200 \mathrm{rpm}$ for transferring speed from the platters storing the bits and the Windows 10 operating system. For simulation of the experiment python programming language were used and analysis is performed using Spyder simulation toolbox.

\section{B. Result Analysis}

Here in carpooling system the analysis is done on the basis of route and number of passenger but in case if number of passenger is same in any route then we will select only that route for travel which has minimum distance so the value of results is shown through table and graphs.

1) Route Selection: There are three possible routes to pick up the passengers Route 1, Route 2, and Route 3. Here in Route 1 total distance traveled by the car is $35 \mathrm{~km}$. Similarly distance traveled by Route 2 is $37 \mathrm{~km}$ while the distance traveled by Route 3 is $30 \mathrm{~km}$. The values of each route is shown in Table II, Table III and Table IV and route distance also depicted through graph of each route which is shown in Figure III, Figure IV and Figure V. After analysis distance of each route it is found that the route 3 will be selected for travel as shown in Table V and Figure VI.

\section{Route 1}

Table II. Node and Distance for Route One.

\begin{tabular}{|c|c|}
\hline \multicolumn{2}{|c|}{ Route One } \\
\hline Nodes & Total Distance \\
\hline 0 & 0 \\
\hline 1 & 0 \\
\hline 2 & 1 \\
\hline 3 & 3 \\
\hline 5 & 7 \\
\hline 7 & 14 \\
\hline 9 & 24 \\
\hline 10 & 35 \\
\hline
\end{tabular}

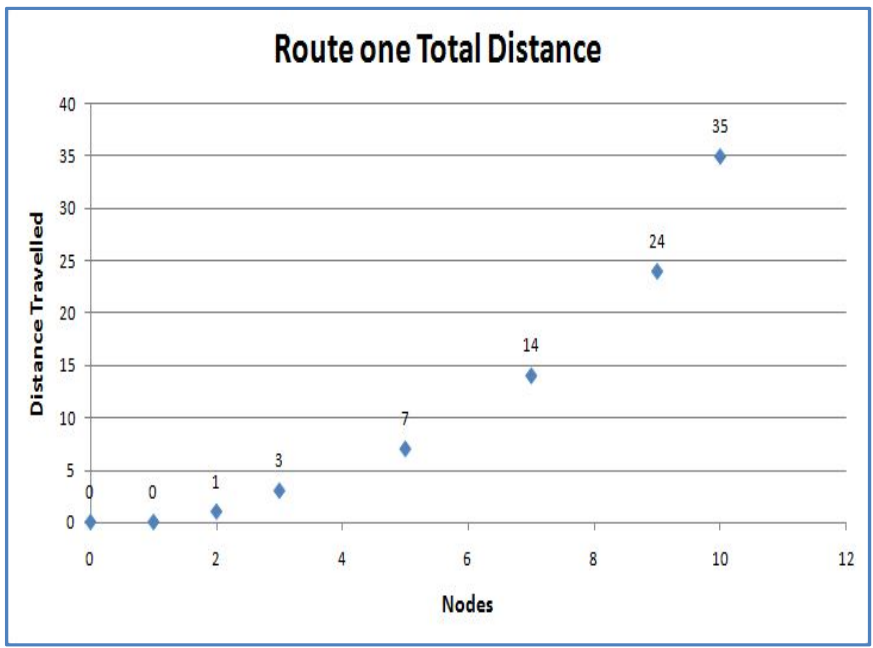

Figure III. Total distance traveled by Route One. 
Route 2

Table III. Node and Distance for Route Two.

\begin{tabular}{|c|c|}
\hline \multicolumn{2}{|c|}{ Route Two } \\
\hline Nodes & Total Distance \\
\hline 0 & 0 \\
\hline 1 & 0 \\
\hline 2 & 1 \\
\hline 3 & 3 \\
\hline 6 & 8 \\
\hline 7 & 16 \\
\hline 9 & 26 \\
\hline 10 & 37 \\
\hline
\end{tabular}

Figure IV. Total distance traveled by Route Two.

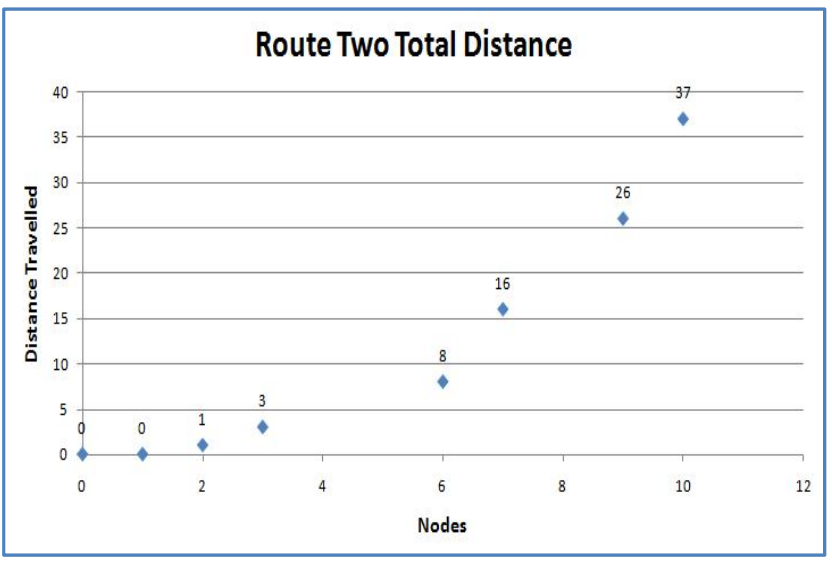

Route 3

Table IV. Node and Distance for Route Three.

\begin{tabular}{|c|c|}
\hline \multicolumn{2}{|c|}{ Route Three } \\
\hline Nodes & Total Distance \\
\hline 0 & 0 \\
\hline 1 & 0 \\
\hline 2 & 1 \\
\hline 4 & 4 \\
\hline 8 & 10 \\
\hline 9 & 19 \\
\hline 10 & 30 \\
\hline
\end{tabular}

Route Three Total Distance

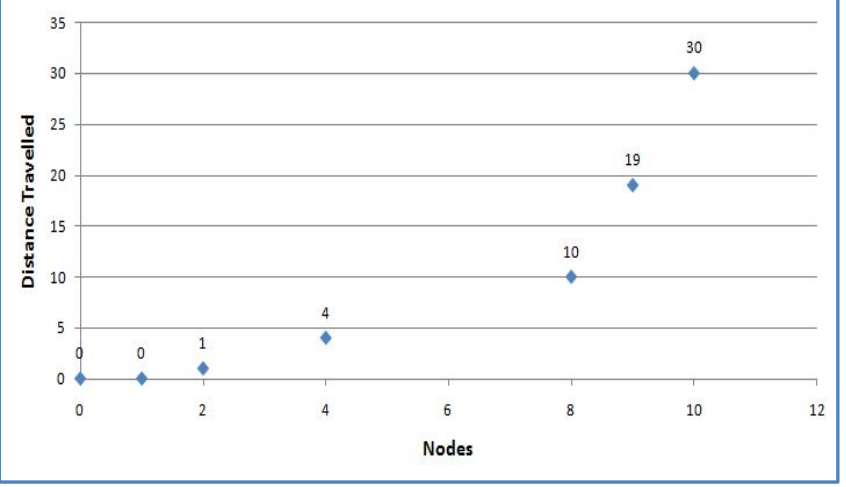

Figure V. Total distance traveled by Route Three.

\section{All Routes}

Table V. Distance comparison for all Routes

\begin{tabular}{|c|c|}
\hline \multicolumn{2}{|c|}{ Distance Comparison } \\
\hline Route & Distance \\
\hline 1 & 35 \\
\hline 2 & 37 \\
\hline 3 & 30 \\
\hline
\end{tabular}

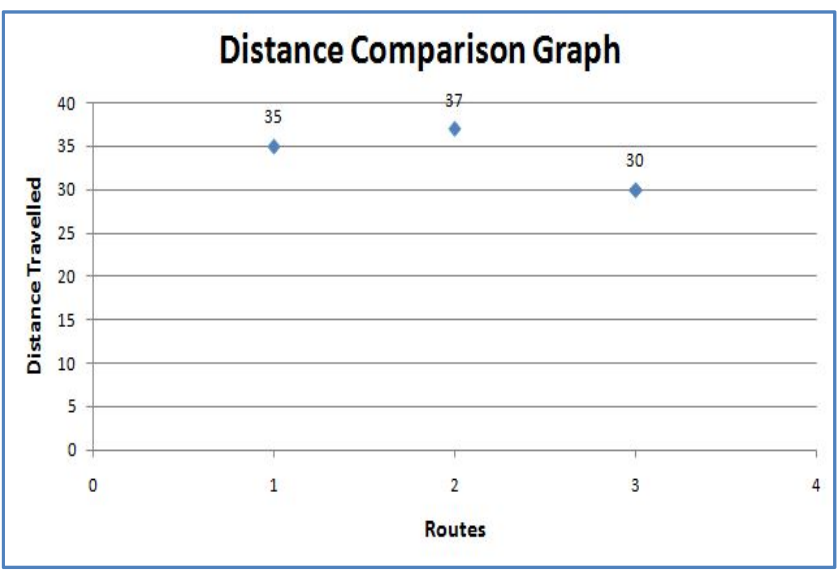

Figure VI : Total distance traveled by all Routes

2) No. of Passengers in Each Rout: Here number of passengers is determined using graph traversal techniques and the no. of passenger in each is shown in Table VI and their comparison graph is also shown Figure VII which is given below.

Table VI. Comparison on basis of no. of passengers between all Routes

\section{No. of passengers Comparison in all Routes}

\begin{tabular}{|c|c|}
\hline Route & No. of Passengers \\
\hline 1 & 3 \\
\hline 2 & 3 \\
\hline 3 & 2 \\
\hline
\end{tabular}




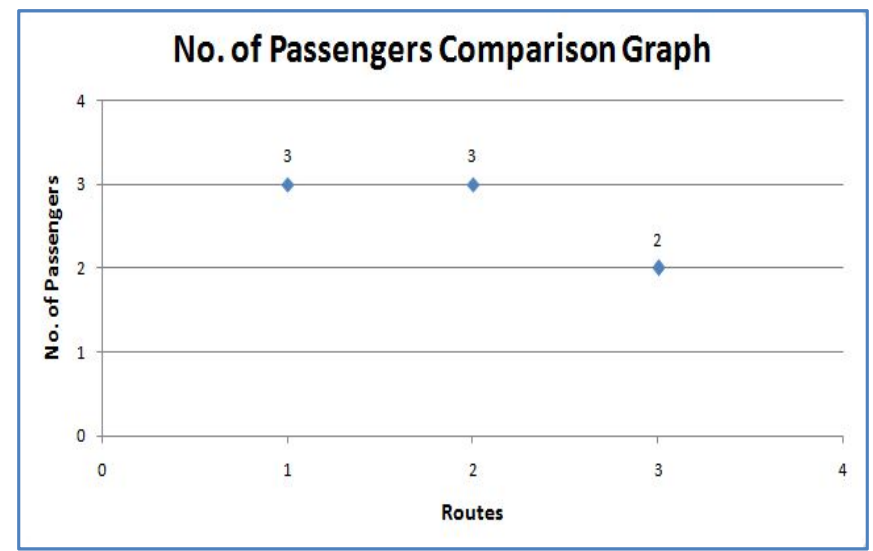

Figure VII. No. of passengers in each Route

Here table VI shows the overall comparison of passenger in each route in which route 1 travel the distance of $35 \mathrm{~km}$ and in that route there is total 3 passengers. Similar in route 2, it travel the distance of $37 \mathrm{~km}$ and has 3 passengers and in route 3 , it travels $30 \mathrm{~km}$ distance but having only 2 passengers. After analysis it is found that route 3 will be selected because in this route it travels less distance than other routes. The comparison of these is shown in Figure VII.

Table VII. Overall Comparison of all Three Routes

\begin{tabular}{|c|c|c|c|}
\hline \multicolumn{4}{|c|}{ Overall comparison } \\
\hline & Route 1 & Route 2 & Route 3 \\
\hline Distance & 35 & 37 & 30 \\
\hline No. of Passengers & 3 & 3 & 2 \\
\hline
\end{tabular}

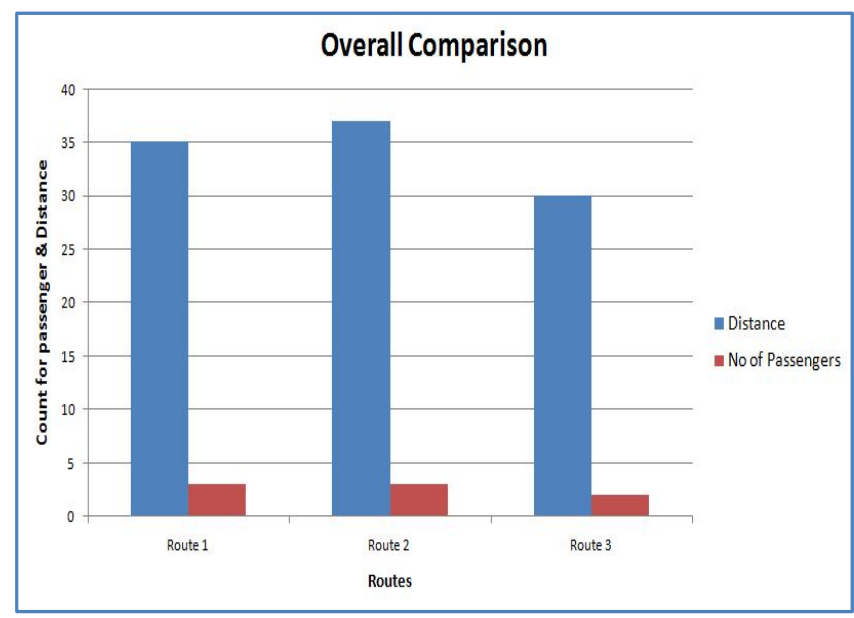

Figure VIII. Overall comparison of Carpooling system on basis of distance and passengers

All the above scenarios are used to determine the shortest path from source to destination assuming the number of passengers present in that route while considering the seating capacity of the vehicle. As per this technique, the shortest route among all routes which is now selected for journey. Now it is time to apply profile matching concept while pick up each passenger from their present location on the selected shortest route. Before the start of each journey, required profile of passenger for each journey is set by the driver. So, that during journey passenger pick up can be made in that manner without conflict and provides more satisfaction to the passenger during the journey. In this carpooling example total 4 no. of passengers are present in $1,2,3$ and 5 places respectively. Out of three no. of possible routes, route 3 is selected where distance covered is $30 \mathrm{~km}$. In this route two no. of passengers are present in the location 1 and 2. Each passenger has its own profile stating about its gender i.e. Any (M \& F), Male (M) and Female (F) along with its smoking status i.e. smoker (1) and non-smoker (0). So, every passenger has two options regarding their smoking status apart from gender. Therefore, in the selected route the various possible profile combinations among gender and smoking status is $(\mathrm{A}, 1),(\mathrm{A}, 0),(\mathrm{M}, 1),(\mathrm{M}, 0),(\mathrm{F}, 1),(\mathrm{F}, 0)$ as shown in Table VIII.

Table VIII. Passenger Profile

\begin{tabular}{|c|c|}
\hline \multicolumn{2}{|c|}{ Passenger wise profile status } \\
\hline Gender & Smoking Status \\
\hline A & 1 \\
\hline A & 0 \\
\hline M & 1 \\
\hline M & 0 \\
\hline F & 1 \\
\hline F & 0 \\
\hline
\end{tabular}

We assume that the profile set by the driver before start of their journey is shown in Table IX.

Table IX. Profile set by driver for a journey

\begin{tabular}{|c|c|}
\hline \multicolumn{2}{|c|}{ Profile set by driver } \\
\hline Gender & Smoking Status \\
\hline A & 0 \\
\hline
\end{tabular}

Let us assume the profile set by the two no. of passenger at location 1 and 2 is given in Table $\mathrm{X}$.

Table X. Profile set by passenger for a journey

\begin{tabular}{|c|c|c|c|}
\hline \multicolumn{4}{|c|}{ Location wise profile set by the passenger } \\
\hline Passenger & Location & Gender & Smoking \\
\hline 1 & 1 & M & 0 \\
\hline 2 & 2 & F & 0 \\
\hline 3 & 3 & F & 1 \\
\hline 4 & 5 & M & 1 \\
\hline
\end{tabular}

Before use of profile matching total no. of passengers in route 3 is 2 i.e. in location 1 and location 2 is present. But when application of profile matching is applied in that route the total no. of passengers selected for the journey is 2 nos. The result will vary as per the profile given by the location 
wise passenger with that of profile set by the driver before start of journey.

\section{CONCLUSION \& FUTURE WORK}

Carpooling is a system which mainly used to reduce traffic on the road and this system is run by the most of the government. The most common idea for this research is to comprehend issues regarding endowment for carpool matching system. As we studied in literature, that the carpooling system also used for reducing the fuel consumption, carbon foot-print and also maintain social integrity. By combining the sharable transport model based on communication network with the social profile of travelers who wants to perform the journeys, then we are able to define metrics which is based on society in order to share the chances and eventually set the priority as per their choice of matching drive appropriately. In this work, for determining the best possible route and no. of passenger in the route we use a graph traversal technique Depth First Search (DFS) and Breadth First Search (BFS). The proposed methodology is mainly used for reducing the traffic of metro cities and it is implemented for the metro cities. In this selection of the route is done on the basis of shortest path and maximum no. of number of passenger available on that route. This proposed system is considered and created in order to find out the effectiveness of such methods and more about its seriousness, the outcome of this experimental research has revealed the optimal solution is of $3+$ travelers will be fabricated in the accompanying route inspite of multiple shared substitute circumstances. In future prospective, first this research can be extended for implementing in multi-hop-car sharing system (i.e. sharing a trip having more than one driver). Prior estimation of travel time can be made to increase forecast of actual travel time of journey can be accepted further. Second, we got an idea from this work is the to maintain "well-being", culture, and trust level are significant in accomplishment of carpooling operations. In order to proliferate the carpooling populace, develop efficacy of the carpool and create long lasting carpool team, emphasis is given over the assimilated study of community network, research excellencies and psychology towards sophisticated matching model for carpooling. Third, security and privacy is the major issue in such carpooling system so in future need to offer such mechanism which also enhances the security level of the system.

\section{REFERENCES}

[1]. Sweta et al., "A Survey to Justify the Need for Carpooling”, International Journal of Soft Computing and Engineering (IJSCE) ISSN: 2231-2307, Volume-5 Issue-2, May 2015.

[2]. GRGUREVIC et al., "APPLICATION OF THE INTERNET OF THINGSCONCEPT INCARSHARING SYSTEM”, https://www.researchgate.net/publication/283153094, October 2015.

[3]. Sofia Liakopoulou et al., "Investigating the preferences of students towards the creation of a carpooling system serving the academic bodies of Thessaloniki city ", Transportation Research Procedia 24 (2017) 425-432.

[4]. Abubakr Alabbasi et al., "DeepPool: Distributed Model-free Algorithm forRide-sharing using Deep Reinforcement Learning”, arXiv:1903.03882v1 [cs.NE] 9 Mar 2019.

[5]. Xiao Qiang et al., "Clustering Algorithm for Urban Taxi CarpoolingVehicle Based on Data Field Energy", HindawJournal of Advanced TransportationVolume 2018, Article ID 3853012, 8 pages.

[6]. Mrs. Chaitrali Dangare and Ms. Gouni Akila, “ An Android based application: Cab pooling”,International Journal of Advanced Research in Computer and Communication Engineering Vol. 5, Issue 3, March 2016.

[7]. Dr. D. Selvaraj et al., "Iot Based Traffic Congestion Monitoring And Management System”, International Research Journal of Engineering and Technology (IRJET) Volume: 05 Issue: 09 | Sep 2018. 